\title{
Determination of Se, Cr, Mn, Zn, Co, Na, and K in Blood Samples of Breast Cancer Patients to Investigate Their Variation Using ICP-MS and ICP-OES
}

\author{
Ozan Toker ${ }^{a}$, Ömer Topdagi ${ }^{\mathrm{b}}$, Sezgin Bakirdere ${ }^{\mathrm{c}}$, Ertugrul Osman Bursalıglu ${ }^{\mathrm{d}}$, Ersoy $_{\text {Öz }}{ }^{\mathrm{e}}$, \\ Önder Eyecioglu ${ }^{\mathrm{f}}$, Yasar Karabulg, Mustafa Çaglar ${ }^{\mathrm{h}}$, and Orhan Içelli ${ }^{\mathrm{i}, *}$ \\ ${ }^{a}$ Department of Physics, Yildiz Technical University, Istanbul, Turkey \\ ${ }^{b}$ Department of Medicine, Atatürk University, Erzurum, Turkey \\ ${ }^{\mathrm{c}}$ Department of Chemistry, Yildiz Technical University, Istanbul, Turkey \\ d Department of Bioengineering, Sinop University, Sinop, Turkey \\ e Department of Statistics, Yildiz Technical University, Istanbul, Turkey \\ f Department of Computer Engineering, Nisantasi University, Istanbul, Turkey \\ g Department of Physics, Yildiz Technical University, Istanbul, Turkey \\ ${ }^{h}$ Department of Medical Physics, Istanbul Medipol University, Istanbul, Turkey \\ ${ }^{\text {i }}$ Department of Physics, Yildiz Technical University, Istanbul, Turkey
}

\section{INTRODUCTION}

Cancer is one of the biggest health problems all over the world and breast cancer is the most common cancer type in women. For many years, despite continuous research into many types of cancer, no definitive results in terms of treatment have been achieved and the number of deaths remains almost the same (1). However, the increasing number of cancer cases treated can be attributed to improvements in diagnosis. About $23 \%$ of cancer cases recorded worldwide are breast cancer (2). It is well known that various diseases are related to the proportional distribution of different elements (3, 4). They play important roles in the structural stability and metabolism of both nucleic acids and proteins, in addition to numerous metabolic and physiological processes in the body (5). Respiratory tract cancer and some others including urinary system, thoracic, skin, lung, central nervous system, stomach, prostate cancers and hemochromatosis in humans were reported to have been related to a deficiency or excess of many elements including

*Corresponding autbor: Orban Icelli

E-mail: oicelli@yildiz.edu.tr

Tel: + 902123834247

Fax: + 902123834100

\section{ABSTRACT}

The aim of this study was to investigate the concentration changes of Se, Mn, Cr, Zn, Co, $\mathrm{Na}$ and $\mathrm{K}$ in blood samples of breast cancer patients. Determination of the elements was performed using ICP-MS and ICP-OES instruments.

Kolmogorov- Smirnov normality tests, Mann-Whitney U tests, Independent sample $\mathrm{T}$ tests and Spearman's rank correlation tests were performed for statistical comparisons. It was found that the concentrations of $\mathrm{Na}$ and $\mathrm{K}$ in breast cancer patients were higher than for healthy people. The Se, Mn, and Cr concentrations were found to be lower in patients with breat cancer. No increase/decrease in $\mathrm{Zn}$ concentrations between the two groups was observed. A positive correlation was found between the distribution of $\mathrm{Zn}$ and $\mathrm{K}$ elements. Independent sample $t$ and MannWhitney U tests demonstrated that statistical differences were observed between patients having the diagnosis of breast cancer and healthy people in terms of the concentrations of $\mathrm{Se}, \mathrm{Cr}$ and $\mathrm{Na}$. The results presented in this study will contribute to the literature by showing the relationship between breast cancer and element concentrations.
$\mathrm{Fe}, \mathrm{Cu}, \mathrm{As}, \mathrm{Cr}, \mathrm{Be}, \mathrm{Cd}$, and $\mathrm{Ni}(6-8)$. Using this imbalance, different diagnostic and/or treatment methods for diseases can be developed. While elements are indispensable for biological structures, they might be toxic for their biological functions if their concentrations are too high (9). Thus, imbalances of the elements might affect some biological processes and their concentrations or ratios are associated with many diseases inculding cancer, autoimmune disease, renal failure, and neurological disorders (10-12).

There are many studies in the literature regarding the relationship of elements and some cancer types. Gecit et al. (9) reported that the $\mathrm{Zn}$, $\mathrm{Mn}, \mathrm{Co}, \mathrm{Ni}$, and Cd levels increased in blood serum of patients with bladder cancer compared to a control group. Another study shows that the $\mathrm{Mg}, \mathrm{Cu}$, and $\mathrm{Zn}$ levels in the blood samples of lung cancer patients are lower than in healthy groups. The same study reported that the $\mathrm{Pb}, \mathrm{Mn}$, and Co levels were found to be higher in comparison to the control group. In addition, blood samples of lung cancer patients showed a positive correlation between $\mathrm{Cd}-\mathrm{Pb}$ and $\mathrm{Mn}$-Fe. In addition, a negative correlation between the Co and $\mathrm{Mg}$ levels was found (13). Mohammadi and his colleagues (14) reported that the $\mathrm{Cd}, \mathrm{Pb}, \mathrm{Hg}$, and Se concentrations 
in different parts of the breast cancer tissues did not show a significant difference. In a bladder cancer work, the levels of $\mathrm{Zn}$ in blood samples of cancer patients were found to have increased (9). In another study, the level of $\mathrm{Zn}$ in lung cancer patients was also found to have increased (13). Even though there are already many studies that discuss the relationship between trace elements and cancer, but more needs to be done to establish possible correlations between the diseases and the concentrations of the elements.

The main goal of this study was to find possible differences in the concentration of elements between breast cancer patients and healthy patients. For this purpose, the concentrations of Se, Cr, Mn, $\mathrm{Zn}, \mathrm{Co}$, $\mathrm{Na}$, and $\mathrm{K}$ were studied under optimum conditions, and different parametric/non-parametric statistical procedures were used in the evaluation.

\section{EXPERIMENTAL}

\section{Instrumentation}

Analysis of the blood samples was performed in the Central Laboratory of Yildiz Technical University using an Agilent 7700 ICP-MS with ORS (octopole reaction system) and a Shimadzu E-9000 ICP-OES. The elements Se, Cr, Mn, $\mathrm{Zn}$ and Co were determined using ICP-MS, while ICP-OES was used to determine $\mathrm{Na}$ and $\mathrm{K}$. The octopole reaction system with a collision-reaction cell contains an octopole ion guide in a stainless steel vessel pressur-

TABLE I

\begin{tabular}{lr}
\multicolumn{2}{c}{ ICP-MS Operating Conditions } \\
\hline RF Power & $1550 \mathrm{~W}$ \\
RF Matching & $1.80 \mathrm{~V}$ \\
Sample Depth & $8.0 \mathrm{~mm}$ \\
Carrier Gas & $1.07 \mathrm{~L} / \mathrm{min}$ \\
NebulizerPump & $0.10 \mathrm{rps}$ \\
S/C TEMP & $2.0^{\circ} \mathrm{C}$ \\
\hline
\end{tabular}

ized with helium gas and was used throuhgout the study. Collision reaction cell is the technology to lessen the interference effects originating from polyatomic species (15).

For sampling, the ICP-MS was used with the Agilent ASX 500 Series autosampler, which was controlled by a computer. All system parameters such as sampling depth, horizontal/vertical position of torch, and nebulizer argon flow rate were optimized to achieve high sensitivities for the analytes of interest. Sensitivity of the ICP-MS was optimized before each set of analyses, and a new optimization was performed in the case of any reduction in sensitivities. The ICPMS and ICP-OES operating settings are listed in Tables I and II. The detection power of ICP-OES was sufficient to determine $\mathrm{Na}$ and $\mathrm{K}$. Hence, these two analytes were determined using ICP-OES under the optimum conditions. In order to measure $\mathrm{Se}, \mathrm{Cr}, \mathrm{Mn}, \mathrm{Zn}$ and $\mathrm{Co}$ at trace levels, ICP-MS was applied under the optimum conditions.

The blood samples were digested in a closed vessel microwave digestion system (Milestone Start D), equipped with an industrial magnetron (single magnetron system with pyramid-shaped diffuser for homogeneous microwave distribution in the cavity).

\section{Reagents and Stock Solutions}

All chemicals used throughout this study were of analytical grade or high purity. Ten percent (v/v)

\section{TABLE II}

ICP-OES Operating Conditions

\begin{tabular}{lr}
\hline RF Power & $1200 \mathrm{~W}$ \\
PlasmaGas & $10 \mathrm{~L} / \mathrm{min}$ \\
AuxiliaryGas & $0.60 \mathrm{~L} / \mathrm{min}$ \\
Carrier Gas & $0.70 \mathrm{~L} / \mathrm{min}$ \\
Exposure Time & $30 \mathrm{sec}$ \\
PPR Speed & $20 / 60 \mathrm{rpm}$ \\
\hline
\end{tabular}

nitric acid solution was used to clean the volumetric flasks. These were rinsed with Milli-Q ${ }^{\circledR}$ deionized water (Millipore Corporation, USA) thoroughly and dried. Stock solutions of $\mathrm{Co}, \mathrm{Se}, \mathrm{Cr}, \mathrm{Mn}, \mathrm{Zn}, \mathrm{Na}$, and $\mathrm{K}$ were prepared daily by taking the appropriate multi-element calibration standard (Agilent Tecnologies, $10.00 \mu \mathrm{g} / \mathrm{mL}$ ) in deionized water. The deionized water was used for all dilutions and the rinsing and cleaning procedures. In the ICP-MS system, high-purity argon gas was used to produce the plasma. Nitric acid $\left(\mathrm{HNO}_{3}, 65 \%\right.$ Merck, Germany), hydrogen peroxide $\left(\mathrm{H}_{2} \mathrm{O}_{2}, 30 \%\right.$, Merck) and deionized water were used in the sample preparation for the microwave digestion system.

\section{Population Studied}

This research was initiated and performed in accordance with the guidelines of the ethics committee of the Medical Faculty of Ataturk University. Eighty individuals, who applied for this study voluntarily to the Medical Oncology Policlinic of Department of Internal Medicine in Ataturk Medical Faculty, were randomly enrolled. A signed consent form was obtained from all participants in accordance with the research approval of Atatürk University/ Faculty of Medicine Ethics Committee. The 80 individuals consisted of 40 healthy and 40 breast cancer patients. The individuals stated that to their knowledge they had no other diseases that might affect the levels of element concentrations for this study. All breast cancer patients in the study were diganosed with invasive carcinoma.

\section{Sample Procedure}

In this study, all analyses were performed with 80 blood samples of which 40 patients had breast cancer and 40 were healthy persons as the control group. The blood samples were digested in a microwave oven before the analysis. For the digestion of each sample, 
a mixture of $2.0 \mathrm{~mL} \mathrm{H} \mathrm{O}_{2} / 6.0 \mathrm{~mL}$ $\mathrm{HNO}_{3}$ was used under the optimum conditions. After the digestion, each sample's volume was completed to $25 \mathrm{~mL}$ volume with deionized water and stored at $4.0^{\circ} \mathrm{C}$. The blank sample solutions were prepared in the same way. The sample solutions were mixed for 15 minutes just before analysis with a shaker. Mass-based sample preparation was applied for the blood samples; hence, the results were expressed as parts per billion (ppb) and parts per million (ppm).

\section{Statistical Analysis}

In order to make statistical comparisons between the patients diagnosed with breast cancer and the control group without cancer with regard to the seven elements (Se, $\mathrm{Cr}, \mathrm{Mn}, \mathrm{Zn}, \mathrm{Co}, \mathrm{Na}$, and $\mathrm{K}$ ), the Kolmogorov-Smirnov normality tests were performed. These tests are applied to decide which statistical procedures should be used in the process of searching the significant differences between two independent groups (patients and control). The independent sample $t$ test is based on group means and widely used to compare two normal distributed groups. The following two hypotheses were tested at the 95\% confidence level: (a) $\mathrm{H}_{0}$ : No difference was observed between the two groups in terms of the value of the trace element, and (b) $\mathrm{H}_{\mathrm{a}}$ : Statistical differences were observed between the two groups in terms of the value of the trace element. When the calculated p-value is less than 0.05 , the $\mathrm{H}_{0}$ hypothesis is rejected, and it can be concluded that the two groups are statistically different from each other. The Mann-Whitney U test as a non-parametric alternative of the independent sample $t$ test is based on group medians and is used when the groups have non-normal distributions. The same hypotheses were tested at the $95 \%$ confidence level. In addition, Spearman's rank corre- lation test was performed in order to find the relationship between the non-normal distributed elements. This non-parametric test shows not only the degree of correlation between the elements, but also gives the direction of relationships.

\section{RESULTS AND DISCUSSION}

The determination of $\mathrm{Se}, \mathrm{Cr}$, $\mathrm{Mn}, \mathrm{Zn}, \mathrm{Co}, \mathrm{Na}$, and $\mathrm{K}$ in the two groups consisting of the cancer patients and the healthy group was performed under the optimum ICPOES and ICP-MS conditions. The accuracy of the method was determined with a certified reference material (CRM) NIST Apple Leaves 1515, (National Institute of Standards and Technology, Gaiterhsburg, MD, USA). The certified values of the CRM and the experimental results are listed in Table III. The obtained results were within the confidence interval of the CRM. The optimized method was used to analyze the blood samples.

Table IV shows the descriptive statistics of the different elements belonging to the control and the patient groups, and also the hypothesis test results of the group comparisons for each element. When the mean values of the concentrations are taken into account, it was observed that while Se and $\mathrm{Cr}$ have a higher value in the healthy group, $\mathrm{Na}$ and $\mathrm{K}$ have higher values in the patient group. No increase or decrease in $\mathrm{Zn}$ concentration was observed between the two groups. In addition, Table IV shows that the constructed $\mathrm{H}_{0}$ hypotheses for $\mathrm{Se}, \mathrm{Cr}$, and $\mathrm{Na}$ are rejected at the $95 \%$ confidence level, and that it could be stated

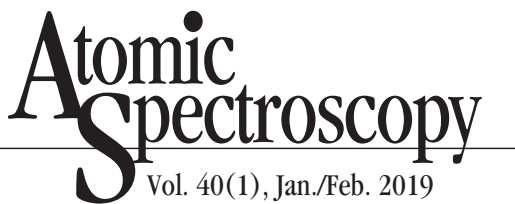

that statistical differences were observed between the patients having breast cancer and the healthy group in terms of the $\mathrm{Se}, \mathrm{Cr}$, and $\mathrm{Na}$ values. However, no evidence was found to suggest the presence of differences between the patients having breast cancer and the control group in terms of $\mathrm{Zn}$ and $\mathrm{K}$.

The mean vaule of the Mn concentration for the healthy group was found to be $18.68 \mathrm{ppb}$ (24 of 40 samples) and $17.13 \mathrm{ppb}$ for the cancerous group ( 7 of 40 samples). Mn was not detected in 33 cancerous samples. Although it is clear that there is a decrease in the concentrations of $\mathrm{Mn}$ in the breast cancer patients, there is not enough data to apply statistical tests for the Mn concentrations. In addition, there were no Co concentrations detected in both groups. Hence, the statistical tests could not be applied to the samples.

The results in Figure 1 show that the Se concentrations decreased in the blood samples from the breast cancer patients. There are some studies in the literature about the elemental distribution for breast cancer patients. Mohammadi et al. (14) analyzed breast tissues and found an increase in Se concentration. Accumulation of Se in the tissues may have reduced its concentration in the blood. There are various meta-analysis studies about the decrease of the element $\mathrm{Mn}$ in breast cancer. The concentration of Mn was found to be lower in the blood of patients with breast cancer which is consistent with the work done by Shen et al. (16). Figures 2 and 3 show that there was a decrease in $\mathrm{Cr}$ concentrations and an increase in $\mathrm{Na}$ concentrations

TABLE III

Experimental Results of CRM NIST Apple Leaves 1515 for Se and Mn

\begin{tabular}{ccc}
\hline Elements & CRM Values $(\mathrm{ppm})$ & Measured Values $(\mathrm{ppm})$ \\
\hline $\mathrm{Se}$ & $0.05 \pm 0.01$ & $0.052 \pm 0.001$ \\
$\mathrm{Mn}$ & $54 \pm 3$ & $54.19 \pm 1.08$ \\
\hline
\end{tabular}


for the breast cancer patients in comparison to the healthy group, respectively. A significant decrease in $\mathrm{Cr}$ also coincides with the work of Bursalioglu et al. (17). While the work of Kolmogorov et al. (18) reports an increase in $\mathrm{Cr}$ concentrations in the hair samples of the breast cancer patients, yet there was a significant decrease of $\mathrm{Cr}$ in the blood samples. The difference between the concentrations is not statistically significant for $\mathrm{Zn}$ and $\mathrm{K}$ as seen in Table IV. On the other hand, statistically significant differences were observed for $\mathrm{Se}, \mathrm{Cr}$, and $\mathrm{Na}$. Figures 1, 2, and 3 show that the boxplots for the $\mathrm{Se}, \mathrm{Cr}$, and $\mathrm{Na}$ concentrations are statistically significant for the healthy and cancer- ous groups. Each box represents the distribution of the relevant element concentrations of the 40 patients. This demonstrates that the pattern for $\mathrm{Na}$ increases, while the pattern for Se and $\mathrm{Cr}$ decreases for the cancerous group. For breast cancer patients, only two elements, namely $\mathrm{Zn}$ and $\mathrm{K}$, are correlated with each other. The coefficient

TABLE IV

Element Values via Statistical Test Results

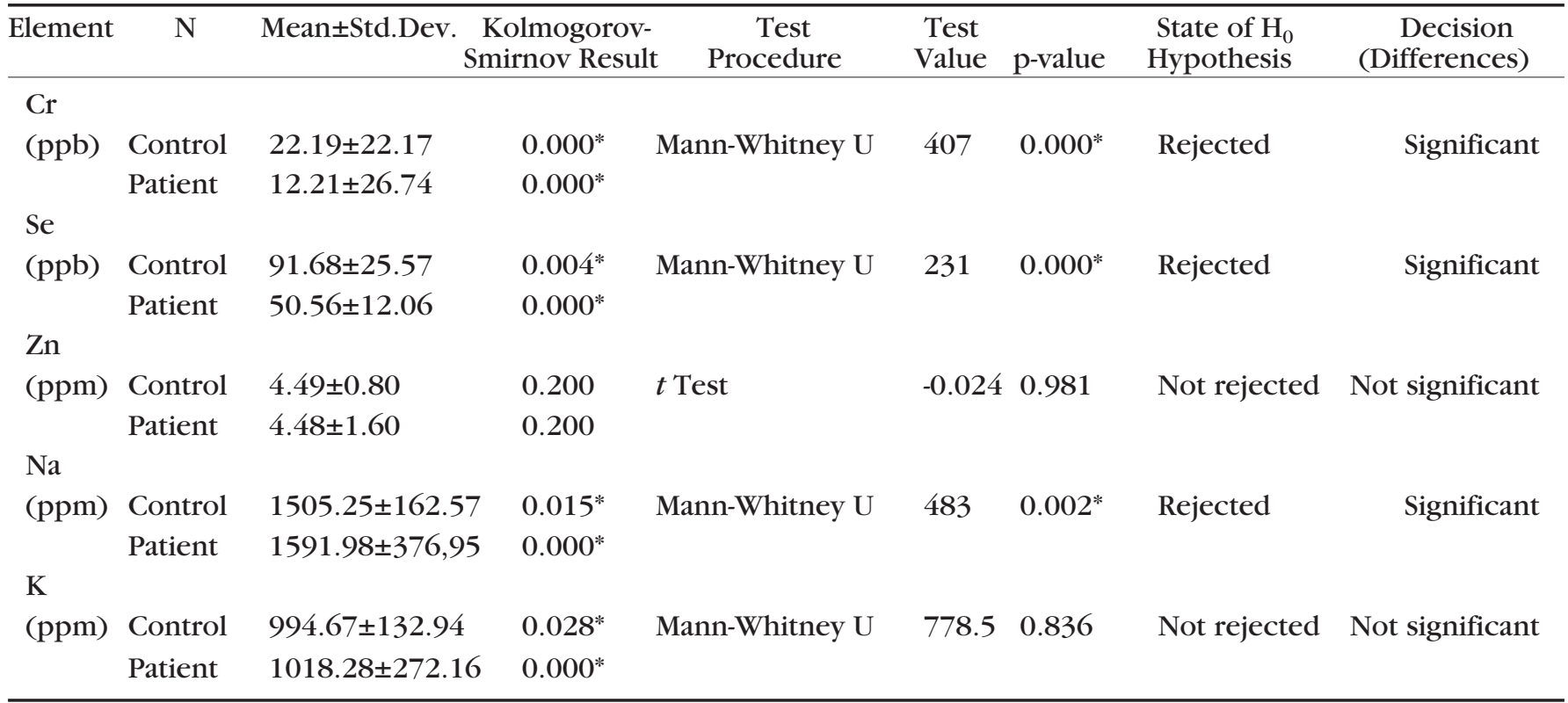

Note: $\left(^{*}\right)$ shows the significant test result, in other words non-normal distributed group in Kolmogorov-Smirnov test and significant difference in Mann-Whitney $U$ test.

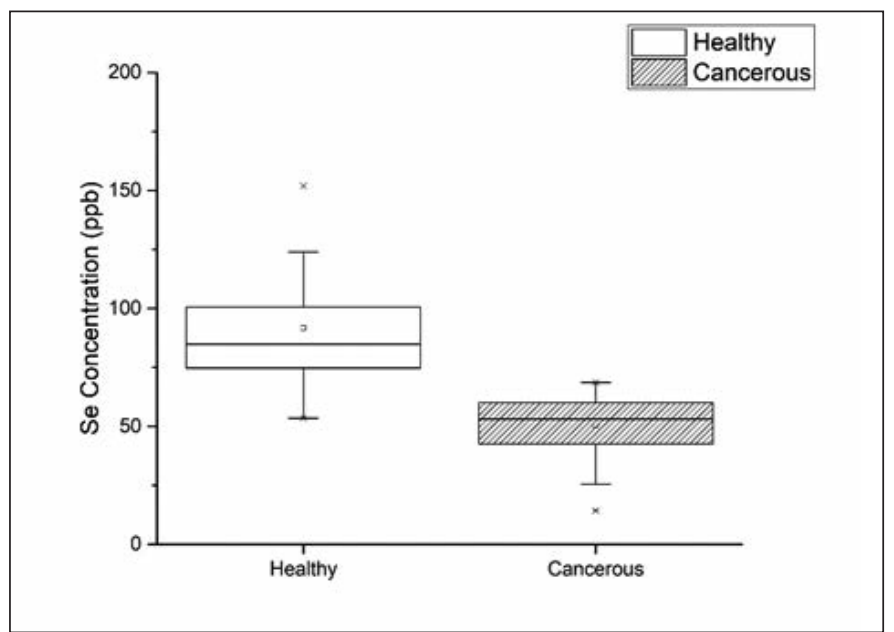

Fig. 1. Boxplot of the Se concentrations for each group.

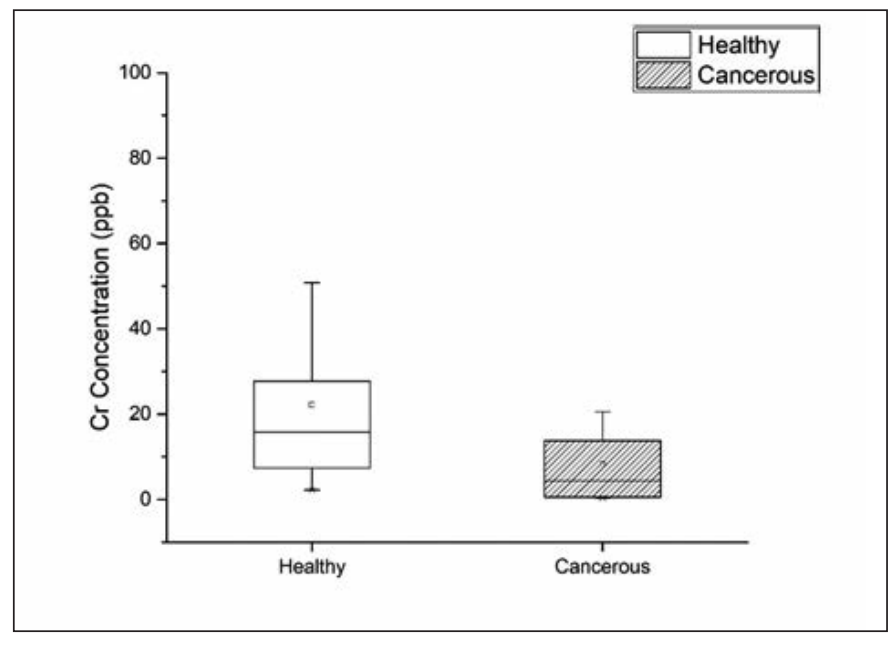

Fig. 2. Boxplot of the Cr concentrations for each group. 


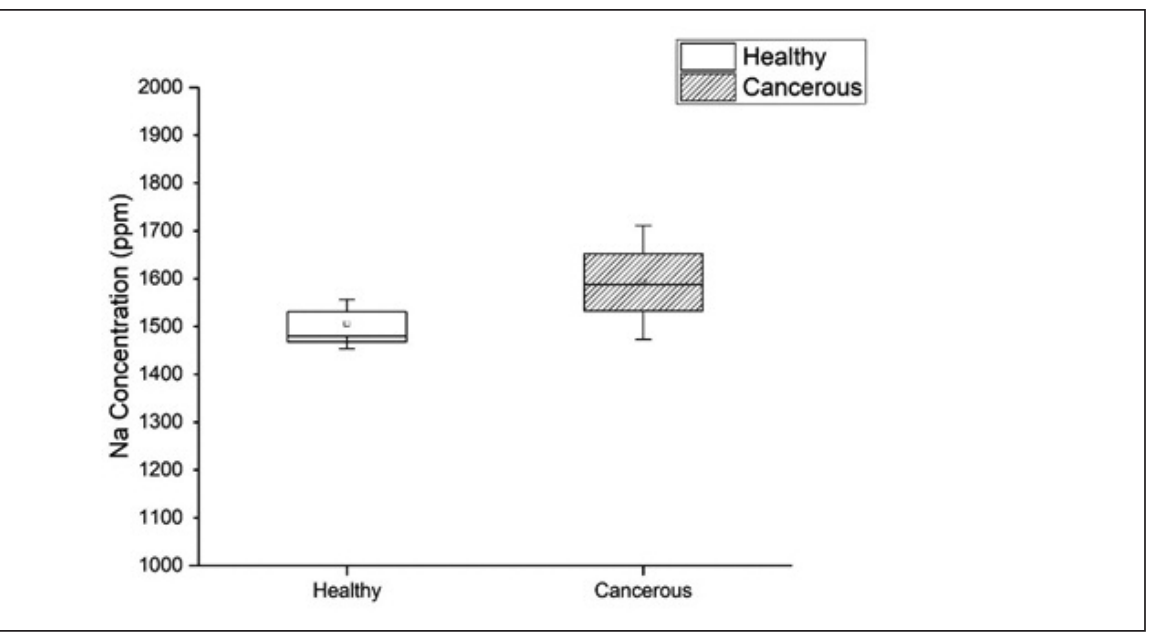

Fig. 3. Boxplot of the Na concentrations for each group.

TABLE V

Correlation Test Results

\begin{tabular}{|c|c|c|c|c|c|c|c|}
\hline & & & $\mathrm{Cr}$ & $\mathrm{Zn}$ & $\mathrm{Se}$ & $\mathrm{Na}$ & K \\
\hline \multirow[t]{15}{*}{ Spearman's } & $\mathrm{Cr}$ & CorrelationCoefficient & 1,000 & & & & \\
\hline & & Sig. (2-tailed) & & & & & \\
\hline & & $\mathrm{N}$ & 40 & & & & \\
\hline & $\mathrm{Zn}$ & CorrelationCoefficient & .294 & 1,000 & & & \\
\hline & & Sig. (2-tailed) &, 066 & & & & \\
\hline & & N & 40 & 40 & & & \\
\hline & $\mathrm{Se}$ & CorrelationCoefficient &,- 232 & -.284 & 1,000 & & \\
\hline & & Sig. (2-tailed) & .151 & .075 & & & \\
\hline & & $\mathrm{N}$ & 40 & 40 & 40 & & \\
\hline & $\mathrm{Na}$ & CorrelationCoefficient & .268 & .236 & .102 & 1,000 & \\
\hline & & Sig. (2-tailed) &, 094 & .142 & .531 & & \\
\hline & & $N$ & 40 & 40 & 40 & 40 & \\
\hline & K & CorrelationCoefficient &,- 026 &, $457^{m}$ &,- 005 &, 102 & 1,000 \\
\hline & & Sig. (2-tailed) & .876 & ,003 & .976 & .532 & . \\
\hline & & $N$ & 40 & 40 & 40 & 40 & 40 \\
\hline
\end{tabular}

of correlation was found to be 0.457 and is statistically significant (p-value $=0.003)$, which means that a positive linear relationship exists between the elements $\mathrm{Zn}$ and $\mathrm{K}$. The correlation test results for all elements are listed in Table V.

\section{CONCLUSION}

The concentrations of $\mathrm{Se}, \mathrm{Cr}$, $\mathrm{Mn}, \mathrm{Zn}, \mathrm{Co}, \mathrm{Na}$, and $\mathrm{K}$ in the blood from patients with breast cancer and a control (healthy) group were determined to find the variation in element concentrations between the patients and the healthy group for possible prediagnosis. Considering the consistency of the element concentrations in the blood samples, it is believed that elements are really an important parameter for blood analysis. The possible differences in the analyte concentrations in total blood could be applied to identify specific breast cancers.

Under the optimum conditions, all samples of this study were analyzed for their elements of interest. The differences were found statistically significant in $\mathrm{Se}, \mathrm{Cr}$, and $\mathrm{Na}$ using the Mann-Whitney U test. While the concentrations of Se and Cr have a significant decreasing pattern, the Na concentrations show significant increasing patterns in breast cancer patients compared to the healthy group. In addition, a positive correlation was found between $\mathrm{Zn}$ and $\mathrm{K}$. The coefficient of correlation between $\mathrm{Zn}$ and $\mathrm{K}$ was found to be 0.457 and statistically significant at the $95 \%$ confidence interval. These variations and correlations are compatible with the direction of the aim of this study. The results presented in this study emphasize and underline the possible relationship between the concentration of certain elements and breast cancer. It is recommended that further studies at the molecular level be performed for a better understanding of the carcinogenic or protective effects of the elements investigated above.

\section{Funding}

This research was supported financially by TUBITAK (2210C) and Yildiz Technical University BAP (2015-01-01-YL04, 832)

\section{Ethical Approval}

Atatürk University Medical Faculty Ethics Committee; 10.24.2016, Session 6, Number: 22.

\section{Conflict of Interest}

The authors declare that there is no conflict of interest.

Received August 8, 2018. 


\section{REFERENCES}

1. B. Weng, W. Wang Q, S. Lin, and Y. Lu, Int. J. Clin. Exp. Pathol. 7, 7028 (2014).

2. A.F. Aristizábal-Pachón, T.L. de Carvalho, H.H.A. Carrara, J.M. de Andrade, and C.S. Takahashi CS., J. Egypt. Natl. Canc. Inst. 27, 217 (2015).

3. P. Neelamegam, A. Jamaludeen, and A. Rajendran, Measurement 44, 312 (2011).

4. N.A. Al Faris, and D. Ahmad, J. King Saud Univ. - Sci. 23, 337 (2011).

5. W. Mertz, Science 213, 1332 (1981).

6. H. Fukuda, M. Ebara, H. Yamada, M. Arimoto, S. Okabe, M. Obu, M. Yoshikawa, N. Sugiura, and N. Saisho, Jpn. Med. Assoc. J. 47, 391 (2004).

7. T.F. Mancuso, Environ. Res. 3, 251 (1970).

8. M. Sandberg, H. Gross, and O.M. Holly, Arch. Path. 33, 834 (1942).

9. I. Gecit, S. Kavak, H. Demir, M. Günes, N. Pirinççi, Ç. Çetin, K. Ceylan, E. Benli, and I. Yildiz, Asian Pacific J. Cancer Prev. 12, 3409 (2011).

10. V. Fuster, L. Badimon, J.J. Badimon, and J.H. Chesebro, N. Engl. J. Med. 326, 310 (1992).

11. M. Shokrzadeh, A. Ghaemian, E. Salehifar, S. Aliakbari, S.S.S. Saravi, and P. Ebrahimi, Biol. Trace Elem.Res. 127, 116 (2009).

12. M.K. Schwartz, Cancer Res. 35, 3481 (1975).

13. U. Cobanoglu, H. Demir, F. Sayir, M. Duran, and D. Mergan, Asian Pacific J. Cancer Prev. 11, 1383 (2010).

14. M. Mohammadi, A.R. Bakhtiari, and S. Khodabandeh, Journal of Toxicology 413870 (2014).

15. M. Gholami, S. Behkami, S.M. Zain, and S. Bakirdere, Scientific Reports 6, 37186 (2016).

16. F. Shen, W.S. Cai, J.L. Li, Z. Feng, J. Cao, and B. Xu, Int J. Clin. Exp. Med. 8, 3671 (2015).

17. E.O. Bursalioglu, F.A. Alkan, U.B. Barutcu, M. Demir, Y. Karabul, B. Balkan, E. Oz, and O. Icelli,
Measurement 100, 19 (2017).

18. Y. Kolmogorov, V. Kovaleva, and A. Gonchar, Nuclear Instruments and Methods in Physics Research A. 448, 457 (2000). 